\title{
De la poupée mécanique à la machine reproductrice
}

Les femmes épineuses dans l'univers urbain des années trente

\section{Beatriz Gómez Gutiérrez}

\section{OpenEdition}

Journals

\section{Édition électronique}

URL : http://journals.openedition.org/agedor/3673

DOI : $10.4000 /$ agedor.3673

ISSN : 2104-3353

Éditeur

Laboratoire LISAA

Référence électronique

Beatriz Gómez Gutiérrez, « De la poupée mécanique à la machine reproductrice », L'Âge d’or [En ligne], 11 | 2018, mis en ligne le 19 décembre 2018, consulté le 17 janvier 2020. URL : http://

journals.openedition.org/agedor/3673; DOI : 10.4000/agedor.3673

Ce document a été généré automatiquement le 17 janvier 2020.

L'Âge d'or. Images dans le monde ibérique et ibéricoaméricain 


\title{
De la poupée mécanique à la machine reproductrice
}

\author{
Les femmes épineuses dans l'univers urbain des années trente
}

Beatriz Gómez Gutiérrez

1 Durant les années trente, Agustín Espinosa fut une figure littéraire reconnue en Espagne par les critiques, les revues et les journaux nationaux, car l'homme, comme l'œuvre, étaient au carrefour de la majeure partie des courants culturels de son époque. Malheureusement, il fut totalement oublié après sa mort à cause de la dictature franquiste. Il est donc nécessaire de récupérer, une fois de plus, cette figure « épineuse » et ses personnages féminins, qui sont à l'image de son époque.

2 Né en 1897, Espinosa est parti à vingt ans des Canaries pour faire des études de lettres à l'université de Grenade. Une fois son cursus universitaire achevé, il s'installe à Madrid pour accomplir sa formation au "Centre d'études historiques", où il rencontre Giménez Caballero, qui va influencer désormais son parcours intellectuel. En effet, Giménez Caballero est l'un des intellectuels les plus engagés avec la Phalange Espagnole, le «mouvement poétique », tel que José Antonio Primo de Rivera, son fondateur, l'a désignée ${ }^{1}$.

3 En 1924, Espinosa obtient son doctorat en études romanes et réussit par la suite le concours de professeur de langue et littérature espagnoles. Après cela, il séjourne à Paris pendant des mois pour compléter ses recherches de doctorat et fréquente le groupe surréaliste grâce à son ami, le peintre Óscar Domínguez, qui avait été baptisé par Breton comme : « le dragonnier des Canaries ».

4 Espinosa se marie en 1932 à Las Palmas avec Josefina Boissier, événement qui n'est pas sans incidence sur l'évolution de son œuvre. Certes, la fidélité maritale éveille en lui un monde de fantasmes érotiques inspirés de son passé, qui sera à l'origine de l'achèvement de Crimen, qu'il publiait depuis 1930 dans des revues littéraires sous forme d'articles.

5 Par ailleurs, de 1932 à 1936, Espinosa participe à l'un des événements les plus importants de l'histoire culturelle canarienne : la publication de la revue Gaceta de Arte. 
Cette revue a su rassembler, à travers ses trente-huit numéros, toutes les tendances dans une époque déstabilisée par les transitions politiques et sociales. Pourtant, influencée par le surréalisme à partir de 1933, la revue se radicalise progressivement et le bourgeois et le capitaliste deviennent les cibles favorites de ses manifestes².

6 Certes, la visite d'André Breton et de Benjamin Péret aux îles Canaries a été la raison essentielle d'une régénérescence dans Gaceta de Arte. La consécration de la composante surréaliste arrive alors avec la publication du $2^{\mathrm{e}}$ Bulletin international du Surréalisme. ${ }^{3}$

7 Un an plus tard éclate la guerre civile et Espinosa se voit relevé de son poste d'enseignant - Crimen ${ }^{4}$ avait déjà été dénoncé depuis la Seconde République comme une œuvre obscène et sacrilège. Certains des congénères d'Espinosa se sont rapprochés du fascisme, d'autres du communisme et, finalement, peu d'entre eux sont restés neutres ou silencieux. Espinosa décide de collaborer avec les journaux phalangistes à la fin de l'été 1936 et ses articles y seront publiés jusqu'à sa mort, survenue trois ans plus tard, après une intervention censée guérir un ulcère.

8 L'œuvre d'Espinosa a été analysée et revendiquée à partir de 1975, après quarante ans d'une dictature qui avait interdit sa publication. Elle a été entièrement récupérée, mais les chercheurs ont décidé d'ignorer les collaborations d'Espinosa avec les journaux phalangistes, car ces articles prêtent à controverse encore aujourd'hui.

9 Il faut tenir compte du fait que, dans le contexte des années trente, les positions des artistes espagnols évoluent vers des engagements extrêmes, et ceci en l'espace de quelques années. D'ailleurs, une phrase résume bien l'atmosphère politique espagnole des années vingt et trente. César Arconada, jeune écrivain d'avant-garde, répond à une enquête réalisée en 1928 - avant même la Seconde République -, par le journal emblématique La Gaceta Literaria, dirigé par Giménez Caballero : "Quelles sont pour vous les idées fondamentales pour l'avenir de l'État espagnol ? - Un jeune peut être communiste, fasciste, tout ce qu'il veut, mais il est exclu qu'il ait de vieilles idées libérales. $»^{5}$

10 Espinosa est né en 1897, un an avant la chute définitive de l'Empire espagnol, après trois siècles d'inexorable décadence. Mort en 1939, il traverse en effet l'une des périodes les plus intenses de l'Histoire de son pays et son œuvre s'aligne sur la majeure partie des courants littéraires des années vingt et trente. Après des poèmes de jeunesse marqués par le modernisme, sa production littéraire prend forme à partir du mouvement d'avant-garde appelé Nueva Literatura, triomphe ensuite grâce au Surréalisme et décline pendant la Guerre Civile avec un style de type fasciste.

11 L'étude de son œuvre se confirme donc comme un outil inestimable pour le déchiffrage de certains paradigmes féminins de l'époque qui traversent les différentes étapes de sa production littéraire ${ }^{6}$. Quatre archétypes féminins, prédominants dans la littérature fin de siècle et celle des premières décennies $\mathrm{du} \mathrm{xx}^{\mathrm{e}}$, séduiront Agustín Espinosa: La " femme fatale » du «modernismo » espagnol, mouvement littéraire qui synthétise le mouvement parnassien, le décadentisme et le symbolisme; la "poupée surréaliste ", dénomination que nous avons choisie d'après une longue lignée de poupées artistiques : de celle Kokoshka en 1918 à celles de Lotte Pritzel en 1919, pour arriver enfin à la poupée de Hans Bellmer, influencée par ces dernières, en $1933^{7}$; la « Femme futuriste ", inspirée des archétypes féminins des années vingt générés par des films comme Metropolis de Fritz Lang (1927), qui montre la création d'un androïde qui prend l'allure d'une femme fatale diabolique; et, finalement, la Femme Phalangiste, inspirée du Futurisme italien et modèle pour les membres de la Section Féminine - branche de la 
phalange espagnole créée en 1934 et dirigée jusqu'en 1977 par Pilar Primo de Rivera, sœur du fondateur.

\section{L'invention de la femme par les avant-gardes}

Représenter la figure de la femme exige une réification, une réduction de la femme à l'état d'objet. Il s'agit, en effet, de s'approprier l'idée de la femme comme n'importe quel autre sujet artistique. Malgré l'abondance de femmes-objets que son époque a véhiculées, Espinosa n'a pas adhéré à toutes ces figures. Ainsi, le vide que ces prototypes de femme ont laissé dans son œuvre révèle, aussi bien que leur présence, quels ont été ses critères de sélection. Avant d'analyser le rapport fictionnel qu'Agustín Espinosa entretient avec les femmes dans son œuvre, il est donc nécessaire de montrer une perspective esthétique de certaines représentations de femmes qu'il a évitées.

Par ailleurs, étant donné l'ampleur des représentations artistiques des femmes au XIX siècle, il est pertinent de se demander quelles ont été les causes de cet essor de la féminité dans les Arts de l'époque. La réponse est peut-être du côté des hommes, car ils sont en grande partie à l'origine de la reproduction de cette profusion de modèles féminins dans la peinture et la littérature à la fin du $\mathrm{XIX}^{\mathrm{e}}$ siècle. Dans son étude de la masculinité, Élisabeth Badinter analyse la crise que celle-ci subit au XIX ${ }^{e}$ siècle. ${ }^{8}$ En effet, cette crise commence selon elle au siècle des Lumières, où la masculinité s'affiche moins qu'au siècle précédent et les valeurs féminines s'imposent progressivement. Ensuite, le xIX siècle connaît des bouleversements économiques et sociaux profonds en Europe, dus aux nouvelles exigences de l'industrialisation et de la démocratie. Les hommes sont de plus en plus nombreux à travailler en usine ou dans l'administration et la valeur traditionnelle masculine, la force, ne leur est plus nécessaire pour gagner leur vie et cesse d'être identifiée au mérite. La nouvelle virilité est identifiée au succès et symbolisée par l'argent, et cela bouleverse des codes culturels très ancrés dans la représentation artistique. De plus, vers la fin du siècle, les femmes prétendent remplir d'autres rôles que ceux de mère et ménagère.

Il se peut donc que cette crise de la masculinité soit à l'origine de l'essor de la représentation de figures féminines aux $\mathrm{XIX}^{\mathrm{e}}$ et $\mathrm{xx}^{\mathrm{e}}$ siècles : les hommes ont perdu leurs repères et s'obstinent à créer des femmes qui puissent exorciser leurs peurs, comme c'est le cas de la femme fatale, ou qui leur permettent, comme les femmes poupées, de dominer ces peurs entièrement.

Or, pourquoi les avant-gardes, qui se prétendent affranchies des courants artistiques du $\mathrm{XIX}^{\mathrm{e}}$ siècle ont-elles encore réifié la figure de la femme au $\mathrm{xx}^{\mathrm{e}}$ ? La fascination pour les objets de ces courants artistiques fait que l'évocation constante des femmes relève presque, dans leur cas, d'une obsession fétichiste qui habite tout artiste d'avant-garde, homme ou femme.

On trouve néanmoins des femmes qui, au sein même des mouvements d'Avant-garde, ont revendiqué, bien avant l'essor des théories queer, leur ambiguïté sexuelle et leur volonté de s'indéfinir en conjuguant à l'infini leur propre image qui devient enfin sujet de désir. On arrive ainsi à ces femmes ambiguës, dont la formule avait déjà été conjuguée par les garçonnes depuis le xix ${ }^{e}$ siècle, que l'œuvre d'Agustín Espinosa n'évoquera jamais. 

veut déjà un manifeste androgyne, développe dans les années vingt une mise en scène constante d'elle-même, où les accessoires et le travestissement jouent un rôle subversif. Elle refuse ${ }^{9}$ théoriquement le caractère déterminé du quotidien et sa rationalité, exhortant à libérer l'étrangeté formelle du réel. Son œuvre contribue ainsi à développer la problématique du genre, de la détermination sexuelle, à travers une représentation de l'humain comme créature duale, hermaphrodite, qui menace l'ordre symbolique du masculin et du féminin ${ }^{10}$.

Ce paradigme de femme hermaphrodite et indéfinie a été complètement ignoré dans l'œuvre d'Agustín Espinosa. Mais il n'est pas le seul. Un autre type féminin, né avec les révolutions scientifiques de la fin du xix siècle, ne trouvera pas d'écho dans son œuvre : les femmes hystériques.

Pourtant, il s'agit d'une dimension inédite de la femme qui a fortement marqué la société de son époque. Les surréalistes vont d'ailleurs célébrer dans l'hystérie « la plus grande découverte poétique de la fin du XIX siècle. ${ }^{11}$ Certes, André Breton et Louis Aragon, tous les deux étudiants en médecine, publient en 1928 un texte intitulé «Le cinquantenaire de l'Hystérie" avec une typographie qui lui donne des allures de manifeste. Ils vont notamment célébrer les photographies des hystériques lors de la phase des crises que Charcot lui-même nommait, phase des " attitudes passionnelles » ${ }^{12}$. Les planches de Paul Richer ${ }^{13}$, médecin interne sous la direction de Charcot, qui expliquent les périodes de l'attaque d'hystérie en quatre périodes ${ }^{14}$, nous montrent des femmes qui se contorsionnent jusqu'à l'opisthotonos ${ }^{15}$ :

Planches de Paul Richer

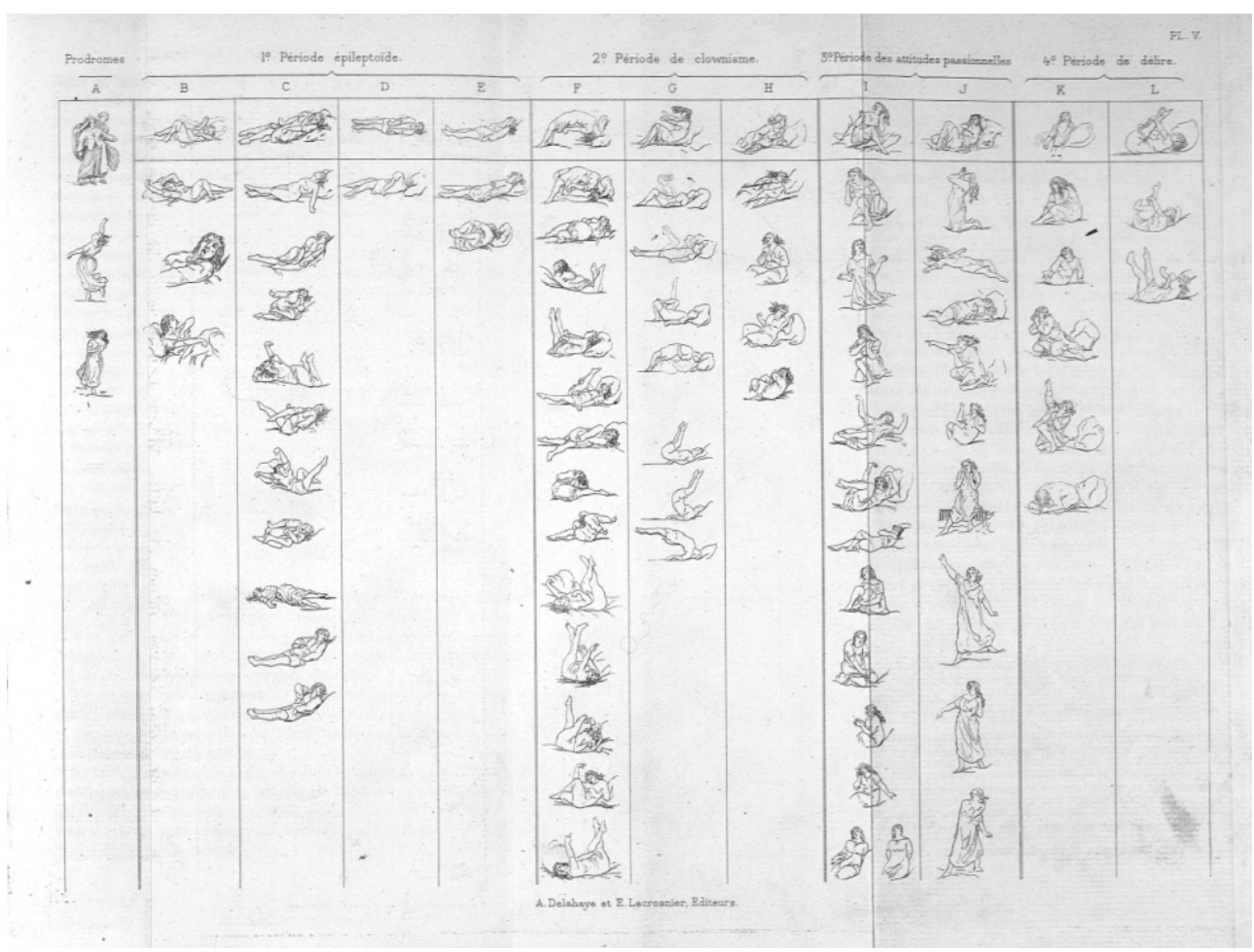

On observe dans les dessins de ces planches comment ces femmes hystériques trouvent, grâce à leur maladie, qui n'est pas organique, le moyen d'exprimer leur désir refoulé. Ce désir, qui a été sous le contrôle des sociétés patriarcales depuis des siècles devient, 
pour la première fois, objet d'étude. Ainsi, l'événement que les surréalistes commémorent est l'acte par lequel les images d'une jeune fille hystérique sont débarrassées du sens morbide: leur regard d'artistes est ainsi capable de métamorphoser une malade, aux gestes lubriques ou grotesques, en poème corporel. La conclusion de leur article montre comment ces femmes hystériques ne cherchent qu'à s'exprimer : «L'hystérie n'est pas un phénomène pathologique et peut, à tous égards, être considérée comme un moyen suprême d'expression. $»^{16}$

21 L'hystérie dévoile finalement une image du corps passionnel féminin, le corps de la jouissance ${ }^{17}$. Ce corps, comme celui de la femme ambiguë, est absent de l'œuvre d'Agustín Espinosa. S'agit-il d'un choix délibéré ou de l'impossibilité pour l'artiste d'appréhender de tels modèles féminins? L'étude des types féminins qui parcourent son œuvre peut nous aider à comprendre pourquoi les garçonnes et les hystériques n'y apparaissent jamais.

\section{Les femmes dans l'œuvre d'Agustín Espinosa}

Les avant-gardes ont pleinement réussi à intégrer le sacré et l'érotisme dans la sphère de la transgression et de l'interdit, ce qui a constitué une révolution dans le monde des $\mathrm{Arts}^{18}$ pendant les trente premières années $\mathrm{du} \mathrm{xx}^{\mathrm{e}}$ siècle. Or, si l'Espagne des années trente est encore loin d'être profane - même sous la Seconde République -, les intellectuels de l'époque sont conscients que le pays n'est déjà plus une exception par rapport au contexte européen. Deux attitudes s'ensuivent: l'une, en quête d'une rupture radicale avec l'univers du sacré, et l'autre, qui réclame pour l'Espagne le rôle représentatif du catholicisme en Occident.

Espinosa refuse de nier l'importance de la tradition catholique. Il professe souvent dans ses articles une véritable fascination pour le christianisme primitif et pour le mysticisme poétique dans la littérature espagnole. Son écriture devient ainsi le rituel par lequel il libère sa violence. Pourtant, les textes d'Espinosa ne se prêtent pas souvent à la confession et, quand cela arrive, c'est toujours sur un ton ludique, sous lequel il se camoufle en permanence. Le "sujet» Espinosa ne peut de ce fait être révélé qu'à travers les « obscurs objets $»^{19}$ de son désir.

Ces « objets » sont, en l'occurrence, des femmes. Elles prennent corps dans son œuvre à travers des métamorphoses récurrentes, mais gardent toutefois, malgré le chaos apparent, une ligne directrice qui permet parfois d'entrevoir l'ombre d'une seule femme. Une femme qui puisse être toutes les femmes à la fois.

\section{De la femme fatale à la femme poupée : décadence, éloge et dissection}

La tradition catholique a nourri l'image d'une gent féminine divisée en deux catégories opposées : l'épouse et la prostituée. Certes, le bien et le mal, le ciel et l'enfer, l'esprit et la chair, ont parfois pu paraître irréconciliables depuis Saint Augustin ${ }^{20}$, et surtout au $\mathrm{XIX}^{\mathrm{e}}$ siècle. Ce dualisme a d'une part obligé les femmes à supporter le poids d'une conception binaire de la réalité, de l'autre, il a permis aux hommes de véhiculer leurs propres angoisses et, parfois même, de canaliser certaines de leurs pulsions. 
Espinosa n'a pas été une exception à la règle. Il s'est servi du dualisme chrétien consciemment ou non - pour s'affranchir de ses craintes, libérer sa créativité et ses conflits intérieurs.

\section{Lesbia}

Lesbia est la première femme fatale évoquée par Espinosa. Voici une sélection des morceaux les plus représentatifs de ce poème, qu'Espinosa jugera plus tard raté :21

En un albo palacio de aljófar y cristales,

sobre un árido monte de esmeril,

vive Lesbia, la diosa de los ojos fatales

y los turgentes senos de marfil.

En las bruñidas cráteras de sus ojos hipnóticos,

tal dos flores malsanas, tal dos filtros eróticos,

guarda Lesbia un maléfico néctar, hechizador

de las vidas vesánicas de los locos amantes

que mueren por beber los perversos instantes

de su extrahumano amor. [...]

Atrevidos donceles, valientes paladines,

Llegan, día tras día, de todos los confines,

Al mirífico alcázar de cristal.

Lesbia les da las tersas magnolias de su seno,

$\mathrm{Y}$ en la mirada verde, misteriosa, el veneno

tenebroso y mortal. [... $]^{22}$

La Lesbia d'Espinosa reproduit fidèlement le modèle de la femme fatale moderniste. D'après son acception littéraire décadentiste, cette femme est destinée à provoquer, je cite : « le malheur, la ruine, voire la perte des hommes » 2 .

Cette femme est ainsi fatale, soit par son refus de la sexualité, qui excite la violence de l'homme, soit par son appétit sexuel exagéré, qui provoque sa peur. Dans le poème d'Espinosa, Lesbia semble correspondre davantage au second modèle : elle se donne à tous et garde, en même temps, le rôle dominant, totalement étranger à celui de l'épouse et de la mère. La manière dont cette "sorcière " garde le contrôle demeure néanmoins féminine, car au lieu de s'imposer par la violence, elle se limite simplement à regarder les hommes comme la Gorgone Méduse ${ }^{24}$.

Enfin, plus qu'un objet de haine, la femme fatale d'Espinosa est simplement un fantasme qui aide l'artiste à surmonter les angoisses liées à sa virilité : elle n'est finalement qu'un miroir où le jeune auteur contemple la terreur que lui inspire la femme $e^{25}$.

\section{Exótica}

Trois ans après «Lesbia », Espinosa compose, en 1920, un sonnet intitulé «Exótica » ${ }^{26}$. Il revient dans ce poème aux sources littéraires décadentes qui avaient inspiré le précédent $^{27}$ :

Yo adoro esas lejanas urbes en que no he estado

Y que sólo conozco por Musset o Baudelaire,

La carne de burdel y el lecho del pecado

Donde sacia la carne su sed de poseer.

Vivir la crapulosa vida del alucinado,

Esa vida perversa que nos hace creer 
Que lo amargo es lo bello y que el beso comprado

Es el beso más dulce que nos da la mujer.

La vesania... Beber ajenjo, fumar opio,

Para mirar la vida por el kalidoscopio [sic]

De lo fatal, de lo fatal, de lo fatal...

Y en una noche alegre y azul de Primavera

Matarme en el impúdico lecho de una ramera

Triste y pálida hermana de Las flores del mal.... ${ }^{28}$ besoin d'évoquer des sorcières maléfiques ou des villes lointaines pour représenter la femme qu'il désire. Il rend hommage à une femme fatale bien réelle, dans un article intitulé «Sous le signe de Démos: éloge de Luisa Santana, danseuse de tango de Las Palmas » :

En cette heure de république et démocratie, d'essor prolétaire, d'aristocratie qui périclite, chantons une femme sans foyer, la chauffeuse d'Éros. Chantons une ouvrière de la nuit, une arrière-petite-fille de Mariana Pineda, une nonne tourneuse médiévale. [...]

Les quartiers marins des ports de la Méditerranée ont inspiré des peintres, des cinéastes et des poètes. Pío Baroja y a promené les héros de ses meilleurs romans. Dans les tavernes de ces quartiers Lord Byron et Baudelaire se sont enivrés. Le cinéma y a cherché le scénario de ses « films » les plus tragiques. ${ }^{30}$

Luisa Santana, image puissante de la femme ouvrière et nocturne représente un mythe du nouveau. Même si Espinosa semble se réjouir du déclin de l'aristocratie dans ces Temps modernes, il établit dès le début la généalogie de Luisa Santana comme l'arrièrepetite-fille de Mariana Pineda. Ce personnage emblématique apparaît également dans Crimen, sous le nom d'Olalla Pineda ${ }^{31}$, qui n'est qu'un jeu de mots : Espinosa mélange l'histoire de Sainte Olalla, martyre chrétienne aux seins découpés ${ }^{32}$ et de Mariana Pineda $^{33}$. En outre, le nom de Santana, qui s'appliquait dans les Îles Canaries aux enfants abandonnés, est l'abréviation de Sainte « Ana ».

Luisa Santa-Ana est à la fois mère, vierge et déesse érotique. Une femme sans passé, déracinée, dont la mission est pourtant de guider les âmes égarées de ceux qui la regardent danser. Cette prostituée, digne d'un temple d'Aphrodite pan-démos Aphrodite «de tout le peuple» - est une composante essentielle de la démocratie républicaine. Espinosa confère à cette femme un destin digne de la tragédie grecque, équivalent du désastreux fatum de la Seconde République espagnole :

Elle doit tomber, tragiquement, une nuit, sous le poignard d'un marin ivre ou les bras forts d'un docker d'âge mûr ou sous les coups de couteau adroits d'un gentil jeune homme. Elle doit tomber amoureuse d'un mousse blond. Elle doit tuer son 
gentil amant d'un soir. Elle doit fuir vite, à l'aube, vers une lointaine Arcadie en fleurs. $^{34}$ l'homme, en véritable "objet» de son désir. Nous avons qualifié les «femmes surréalistes » d'Espinosa de « poupées » en faisant allusion à l'œuvre de Hans Bellmer ${ }^{36}$, dont il a pu admirer les photographies de la «Poupée » en 1935, lors de l'exposition surréaliste de Tenerife ; or, il faudra aussi rendre compte de l'appropriation poétique du corps de María Ana, avec lequel Espinosa joue cruellement, comme s'il s'agissait d'une poupée.

\section{Miss X}

Espinosa inaugure son culte de la poupée dans un article de 1929: "Le costume de marié $\aleph^{37}$. Braulio est frappé d'un coup de foudre immédiat devant une poupée qui a une perruque blonde et des yeux bleus très brillants :

Braulio arrêta un jour ses yeux devant la perruque blonde et les yeux bleus de Miss X. Ce jour-là, il nota dans son journal, tout réjoui : « le 12 avril 1929. Miss X apparaît dans ma vie. Dorénavant j'irai plus sûr de moi à travers le monde. J'ai deux lanternes célestes, pour les embuscades du diable. [...] J'ai une fiancée, fiancée d'un mètre et douze centimètres, que je pourrai ranger dans le coffre de la cabine quand je voudrai voyager seul. Ou l'habiller en Alsacienne, pour l'offrir comme cadeau de Noël à mes futurs fils, qui ne sauront pas que c'est leur maman déguisée jusqu'au jour où je leur dirai, presque ému : mes chers petits-enfants, on a perdu la poupée de Noël. » $[. . .]^{38}$ 
Espinosa réalise ici un hommage à la Miss X du poète Rafael Alberti ${ }^{39}$ et peut-être aussi, à Augustine la patiente de Charcot, dont le surnom anonyme était X.L. Or, la poupée d'Espinosa, au lieu de planer dans le ciel comme le personnage d'Alberti ou d'exprimer ses pulsions comme Augustine l'hystérique, semble condamnée à finir dans un coffre ou pire encore, à être délibérément égarée. Il y a dans l'article d'Espinosa une volonté de provocation évidente et une misogynie qui se veut drôle, mais qui favorise la catharsis de désirs refoulés : déguiser la femme à souhait, pour qu'elle ne cesse d'être à l'image du désir de son amant, s'en décharger si elle devient un fardeau.

\section{María Ana}

Après Miss X, on rencontre l'énigmatique María Ana un an plus tard, dans un poème assez singulier. Certes, Espinosa verse dans cette idolâtrie littéraire qui durera des années, en consacrant une ode à ses " aisselles non épilées $»^{40}$ dont nous ne citons que le début :

Hablemos de María Ana y de sus axilas sin depilar.

Hablemos también del Destino.

Agustín Espinosa, alcantarillero de sueños adversos

Agustín Espinosa, coleccionador de azucenas innumerables.

Enamorados de María Ana.

Jinetes de su sexo único.

María Ana, vacilante entre los dos Agustines.

[...]

María Ana no había comprado nunca hojas Gillette.

María Ana tenía 489 vellos en el hoyo de cada una de sus axilas.

Y esto lo vieron coleccionador y alcantarillero.

Únicamente por sus vientos propios eran luego uno y otro gobernados. ${ }^{41}$

Le poème commence par une série de treize vers en italique qui introduisent une histoire d'amour appartenant au passé : amoureux de María Ana, Agustín Espinosa s'apprête à exorciser cet amour et le poème devient un chant de deuil à une femme perdue $^{42}$.

En effet, on peut situer la rencontre entre Espinosa et María Ana à l'époque où il faisait ses études à Grenade. Après avoir lu le poème, son colocataire de l'époque lui écrit une lettre où il le confirme :

Cher Agustín, je suis arrivé hier soir chez moi - chez nous - et j'ai trouvé ton Ode à María Ana, notre María Ana, celle aux aisselles poilues et au corps insipide. Le seul document publié d'une saison de nos vies. [...] Cette époque de bohème [...] douloureuse et douce comme le sourire d'une aisselle de notre María Ana. ${ }^{43}$

Cette synecdoque de la femme, réduite à une zone cachée de son corps, demeure non seulement le signe d'une diversion stylistique, mais aussi d'une tentative d'appropriation de ce corps obsédant à travers la dissolution de sa totalité.

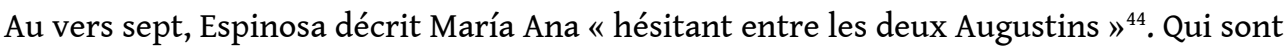
ces deux Augustins Espinosa? Ce sont les deux revers d'un homme. María Ana, femme fatale qui « hésite entre les deux » étant elle-même duelle, est la seule capable d'aimer le vrai Espinosa, collectionneur et éboueur à la fois, car elle peut accepter d'être souillée sans perdre pour autant sa nature de lis.

On peut supposer que dans la vie réelle cette histoire s'est terminée, mais que le je poétique, ce double « Agustín Espinosa », ne peut pas oublier María Ana. Il est donc, par 
extension, hanté par María Ana tout entière et, à défaut de la posséder corps et âme, le je décide alors de la désintégrer en deux aisselles pour détenir enfin cette «enfant poilue $»^{45}$.

\section{Crimen} verbe et des temps de leurs actions, à retenir l'attention du lecteur, comme s'il s'agissait d'un roman policier. En effet, il faut d'abord connaître la scène du " crime », afin de connaître les causes de cet acte suprême de libération, chez un personnage abusé par une femme fatale, digne des « héroïnes » perverses du roman noir :

Il était marié avec une femme à la beauté arbitraire afin qu'en dépit de son insultante jeunesse, sa beauté fût supérieure à celle-ci.

Chaque jour, elle se masturbait contre lui tandis qu'elle embrassait le portrait d'un jeune gandin à la moustache douce et sombre.

Elle pissait, déféquait, crachait - quand elle ne vomissait pas - sur le petit homme faible et amoureux, satisfaisant ainsi, par la même occasion, aux exigences inextinguibles et guerrières d'une sexualité dont elle était à la fois la seule maîtresse et l'unique officiante.

C'est homme, c'était moi.

Ceux qui n'ont jamais possédé une femme de la beauté et de la jeunesse de la mienne, ne peuvent porter un jugement objectif sur un cas moins insolite et extraordinaire qu'il n'y parait à première vue.

Elle pensait que sa vie ne serait plus que crachats, vomissements, masturbations et qu'interminablement elle pisserait et déféquerait sur moi.

Mais une nuit, du balcon de notre chambre à coucher, je la précipitai sous un train et sanglotai jusqu'à l'aube, au milieu des condoléances fondamentales des voisins, versant des larmes sur ce suicide inexplicable et inexpliqué. ${ }^{47}$

51 Cette femme ressemble à une poupée mécanique dont la seule activité serait celle de rejeter les déchets de son organisme sur son amant. Après les poils des aisselles de María Ana, Espinosa défie encore davantage la représentation érotique en introduisant des sécrétions de tout genre dans l'acte sexuel.

Ce passage de la troisième à la première personne semble indiquer que le narrateur n'ose pas s'avouer victime. Mais le narrateur est capable de prendre la parole dès qu'il s'agit d'expliquer que, d'une part, sa situation n'est pas aussi insolite qu'elle n'y paraît et que, de l'autre, il a enfin décidé une nuit de tuer son bourreau. L'homme victime de la femme fatale redevient ainsi le maître.

Par la suite, Espinosa ne peut résister à rendre évidente l'intertextualité dans laquelle il cite explicitement María Ana :

L'élégie de María Ana, qui fait la matière de ce livre, je l'ai écrite en une heure d'inconscience et d'oubli relatifs. Une élégie à une María Ana qui vivrait aujourd'hui, en 1930, qui serait dans mes souvenirs antérieure au crime, mais postérieure aux séances de vomissements et de crachats. Une María Ana remontant à mes lointaines années d'étudiant en philosophie et en lettres. La María Ana, enfin, $\mathrm{du}$ jeune gandin à la moustache douce et sombre. Ou mieux: une élégie telle qu'aurait pu l'adresser à María Ana ce jeune homme aussi odieux qu'heureux. 
Pour lui permettre d'échapper à mon crime - au poids du train sur elle et à la panique engendrée par sa chute -, j'ai écrit un récit intitulé «Le revenant ou le costume de marié ».

Ici repose María Ana sur sa couche nuptiale immaculée, enveloppant son adieu dans un sourire d'emprunt. Et si je l'ai déguisée en Miss X, c'est pour mieux la dépouiller de ses ténèbres andalouses qui m'auraient contraint à la précipiter sous d'autres express matinaux. ${ }^{48}$

Après avoir expliqué la nature «sensationnelle» et «unique» de son "grand assassinat passionnel», qui est un crime "de roman " plutôt qu'un crime réel, le narrateur raconte au lecteur ce qu'est devenue sa vie depuis son crime :

Aujourd'hui, je ne vis plus que pour cet écrin de velours blanc où je conserve deux yeux bleus, trouvés par l'aiguilleur sur la voie ferrée, à l'aube menstruelle de mon crime, parmi des restes sanguinolents. ${ }^{49}$

Les yeux de la victime sont bleus, comme ceux de Miss X, où Braulio avait vu un avenir rassurant ${ }^{50}$. Le narrateur semble, encore une fois, préférer la dissolution de l'être aimé pour pouvoir l'enfermer, dans un coffre ou dans un étui, et conserver ainsi la pureté de cet amour impossible. Voilà donc un exemple de fétichisme in extremis, tel que le décrit Freud.

Après cette introduction à la scène du crime, un parcours s'engage à travers les quatre saisons. Le printemps compte cinq chapitres.

Espinosa intitule le premier chapitre du printemps «Lune de miel» et il fut écrit à l'époque même de son voyage de noces. Il commence: «Je m'étais endormi entre les vingt seins, les vingt bouches, les vingt sexes, les vingt cuisses, les vingt langues et les vingt yeux d'une même femme. $\|^{51}$ Tous les organes se multiplient, mais la femme reste unique. Or, le réveil se révèle une expérience horrible. Le protagoniste est nu, crucifié dans son lit nuptial par des mains féminines. Il est couvert d'une armée de bestioles. Apparaît alors la tête d'une femme brune qui, pour la première fois, prend la parole :

- Je peux te le dire à présent, mon pauvre vieux trompé, mon grand cocu émacié, je te hais. Jamais plus tu ne toucheras mes seins, aujourd'hui caressés par des mains d'anges. Désormais, mon sexe se promène dans les maisons closes des ports de la Méditerranée, visités par de jeunes marins audacieux, et mes pieds partent à la poursuite de bras décloués et de lèvres vierges. Pour toi, j'ai conservé cette tête tronquée, ces yeux timides, et cette bouche proférant d'éternelles insultes. ${ }^{52}$

C'est la tête de María Ana qui vient de l'au-delà pour condamner le protagoniste, car il a détruit son « Destin ».

Le chapitre appartenant au printemps qui suit la lune de miel s'intitule « Le chapeau héroïque ». Il fait partie d'un nouveau rêve raconté par le narrateur. Les symboles oniriques sont assez évidents : l'exploit du chapeau consiste à avoir libéré son désir, excité auparavant par une chaussure, élément fétichiste par excellence. Un homme qui passe, tête nue, prend ce chapeau. Soudain, ce personnage devient le narrateur et prend dans sa main, comme si elle avait six ans, une femme qui en a plus de quarante. Cette femme obèse est aussi petite que Miss X, ce qui permet au protagoniste de la hisser sans peine dans des tramways. Elle refuse ensuite de mettre le chapeau, même si le narrateur essaie de la convaincre en arguant que la différence entre les sexes est totalement arbitraire. Ne la convainquant pas, le narrateur se voit obligé de recourir à la force et de la faire souffrir pour enfoncer sur sa tête ce chapeau trop petit : "J'avais dû la faire horriblement souffrir, car, lorsque nous sortîmes de la boutique, elle 
pleurait. $\aleph^{53}$ On trouve le lendemain le cadavre d'une enfant de six ans portant un chapeau d'homme, maintenu par une grosse épingle, qui a perforé sa masse cérébrale.

Les allusions au viol sont à tel point évidentes qu'il n'est pas nécessaire de les signaler. Il faut noter que ce crime abject s'acharne sur la tête de l'enfant, comme s'il s'agissait de se venger de la tête de María Ana. Cette dernière métamorphose en enfant n'est, en réalité, qu'une nouvelle version de la poupée Miss $\mathrm{X}$ avec son mètre douze, qui est maintenant débarrassée de ce faux déguisement de poupée, pour devenir une enfant violée.

Le printemps se poursuit avec un texte qui s'intitule «la Nuit de Noël de Figaro $"^{54}$. Il s'agit d'un dîner de Noël où un homme de cinquante ans, au visage fardé et habillé d'un manteau de femme sur lequel on lit l'inscription : « $\mathrm{M}^{\mathrm{a}} \mathrm{A}$. célibataire, 16 ans, inconnue » ${ }^{55}$, va servir de plat principal.

À ce propos, il est intéressant d'évoquer le festin qui fut mis en scène lors de l'ouverture de l'exposition surréaliste de 1959, intitulée ÉROS. Ce festin nu, comme dirait Burroughs, fut imaginé par l'artiste Meret Oppenheimer, une des femmes qui fit partie du groupe surréaliste et qui crée, comme Espinosa, un festin où c'est la femme qui devient le plat principal. On voit donc comment les femmes s'approprieront par la suite, au sein du mouvement surréaliste, les mêmes représentations féminines que les hommes avaient privilégiées pour exorciser leurs obsessions.

63 La dérive fatale arrive sous forme d'un "Épilogue dans l'île des malédictions » où tous les souvenirs se mélangent dans une malédiction qui condamne définitivement le narrateur:

«Et jusqu'ici je n'ai amené - écris-je - ni ses cuisses de neige, ni ses mains habiles, ni même ses yeux démesurément ouverts à l'intérieur d'un écrin sans légende... » [...]

Qui est cette femme qui s'est jetée à la mer pour ne plus avoir à se dévêtir devant des marins, des commerçants et des soldats, si fragile, si blanche, que son corps, un moment sur l'eau, s'est confondu avec l'écume marine et avec le sillage de la lune et avec les ailes des mouettes? [...]

Une nuit, je me regarderai dans le miroir, éclairé par la lumière d'un candélabre que je tiendrai à la main, je verrai poindre à travers le cristal, ma vieillesse imprévue, précipitée dans une obscurité sans proue, livide ${ }^{56}$.

Le narrateur se demande encore qui est cette femme. Et l'on apprend finalement que la victime de ce crime exécrable s'est en réalité suicidée ! Ainsi, Espinosa apporte à la figure de la Femme Fatale une nouvelle donne : non seulement il réussit à se délivrer du destin fatidique auquel sont condamnés ceux qui ne peuvent résister à son pouvoir fatal, mais il montre à la fin du roman, que María Ana est en réalité une victime du désir des hommes!

On arrive ainsi à la figure de la femme sportive des avant-gardes, qu'Espinosa célèbre souvent davantage pour sa plastique que pour ses compétences intellectuelles. Cette vision superficielle de la femme moderne ne fait qu'anticiper l'avènement des femmes endoctrinées par la section féminine de la phalange espagnole, dont le sport sera l'une des composantes essentielles pour asservir le corps de la jeune femme, qui ne doit désirer rien d'autre que le mariage et la maternité. 


\section{De la femme sportive à la femme phalangiste : l'activité physique comme endoctrinement}

Vers la fin des années vingt, les avant-gardes introduisent en Espagne un idéal de femme qui se veut nouveau. Cet archétype de femme moderne pourrait se réduire à un seul mot - anglais, évidemment: la "tenniswoman", modèle importé de France et d'Angleterre où les femmes ont quelques longueurs d'avance. Les écrivains de l'époque s'inspirent des premières championnes espagnoles, comme Lucía de López Banús ou Lilí Álvarez ${ }^{57}$, qui furent des stars durant la Seconde République.

Féru de nouveauté, Espinosa exalte le mythe de la femme moderne, même s'il n'a pas témoigné d'une grande considération à leur égard : en effet, parmi les 565 personnalités réelles citées dans son œuvre ${ }^{58}$, seulement vingt-trois sont des femmes, même pas un quatre pour cent du total.

Au-delà des personnalités célèbres qu'il cite, Espinosa choisit 3 femmes anonymes pour amorcer sa construction de la femme moderne. La première de ces femmes est une amie nommée María del Pilar Lozada, les autres, sa future belle-sœur et son épouse ${ }^{59}$.

\section{$M^{a}$ del Pilar Lozada} gardes, défini par opposition au mythe canarien de Dácil, qu'Espinosa revitalise en 1931 afin de l'intégrer à son univers créatif. L'article s'intitule «Bilans de mer et de terre : le contre-mythe de Dácil $»^{60}$.

70 la suite de la conquête des îles. Dácil est une princesse aborigène ${ }^{61}$ de l'actuelle île de Tenerife qui tombe amoureuse du capitaine espagnol Guillén Peraza, venu conquérir les Canaries. Espinosa recrée alors le mythe de Dácil à travers l'adaptation du personnage à la modernité qu'il attribuait aux femmes des années trente, en l'occurrence María del Pilar Lozada. Cette modernité, qui consiste essentiellement en la pratique du sport et de la conduite automobile, se traduit dans le cas de Dácil par une évolution de son regard sur le monde, suscitée par sa condition d'îlienne :

Elle ne regarde pas vers la mer, la fille blonde, mais vers la terre. Elle a entre ses mains une raquette de tennis. Sur son corps, une légère robe sportive. Ses pieds chaussent des sandales blanches.

Avant, c'était l'éventail en plumes, la ronde crinoline, le cothurne sans gravité. Le théâtral, le fastueux. Ni la Grecque de Périclès ni la bergère de France. Maintenant, c'est la raquette déplumée, la sandale homérique et le pull ajusté.

Elle a perdu la symphonie en blanc, son ton. Elle ne sert même pas à tisser un voile de mariée, ni à broder le drap nuptial.

Le mythe de Dácil est mort. ${ }^{62}$

Dácil a laissé derrière elle ses accessoires - bien que ses sandales soient encore le signe de la Grèce ancienne - pour devenir une figure minimaliste : sa raquette donne le ton de son époque. Elle n'attend plus l'être aimé, qui viendrait en bateau pour lui offrir un destin, elle ne regarde plus vers la mer et elle a perdu la couleur blanche dont sont faites les robes et la literie des mariées.

Cette définition d'une femme pragmatique contraste alors avec le mythe de Dácil, qui est pour Espinosa celui d'une jeune fille naïve, amoureuse et pleine d'espoir. Espinosa 
annonce ainsi, sur un ton lugubre, la mort du mythe de Dácil, qui était imprévisible au début du texte. ${ }^{63}$

Toutefois, en dépit de la mort de Dácil, annoncée en 1931, Espinosa revient sur ce mythe l'année suivante, à l'époque où il se fiance avec sa future femme, Josefina Boissier. Tenant compte du fait que le contre-mythe de Dácil est dédié à une certaine María del Pilar Lozada une année plus tôt on peut imaginer que le mythe d'une Dácil amoureuse est récupéré par Espinosa quand il est sûr d'une réciprocité affective. Il écrit alors "La petite infante de Nivaria ${ }^{64}$ et remythologise le personnage de Dácil, qui se trouvait dévalué depuis son article " contre-mythique ».

74 Dácil représente désormais pour Espinosa le mythe de la femme d'avant-garde, sportive, cosmopolite et androgyne - «Elle était plus une capitaine Castillo qu'une petite infante insulaire $»^{65}$. Une symbolique de la jeunesse et de la puissance adoptée par les avant-gardes pour définir un nouvel idéal esthétique, qui sera abondamment développé par la suite pour la caractérisation de l'homme phalangiste -mais jamais de la femme ${ }^{66}$.

\section{Lolina}

Durant quatre mois et juste avant son mariage le 14 juin, Espinosa rédige douze chroniques dédiées à sa future belle-sœur, d'abord intitulées "Lettre hebdomadaire à Lolina», puis, dès qu'il ne peut plus suivre le rythme hebdomadaire, "Lettre provinciale à Lolina ».

Lolina $^{67}$ incarne, comme Alice ${ }^{68}$ dans l'œuvre de Carroll, une personnalité à rebours, en écho à celle d'Espinosa. Elle rejoint ainsi le mythe de l'enfant qui ose dépasser la réalité : tout comme Dácil, elle est de l'autre côté du miroir, du côté de la mer et du rêve où rien n'est impossible. Il n'est donc pas excessif d'imaginer qu'Espinosa ait pensé à la relation de Lewis Carroll avec Alice Liddell alors qu'il entreprend ces lettres hebdomadaires.

En 1932, Lolina a seulement douze ans ${ }^{69}$ et elle rêve de voyages. C'est la raison pour laquelle Espinosa lui recommande la lecture de l'essai de José Miquelarena - Pourtant, ils n'ont pas des bananes - chronique d'un séjour de cet auteur aux États-Unis :

$\mathrm{Tu}$ pourrais faire - "preflapper" authentique, pensant à celle dont Mr Waldo Franck fit son portrait de la « flapper » new-yorkaise -, tu pourrais faire depuis ton propre lit [...] pendant que [ta main] droite tient un livre de 600 pages, un voyage autour du monde [...]..$^{70}$

« Flappers » est un néologisme inventé après la Grande Guerre, pour décrire un nouvel archétype féminin: les jeunes femmes américaines, délurées et oisives, qui ne cherchent qu'à s'amuser, profitant intensément de la vie. Zelda Fitzgerald, icône des années vingt, surnommée par son mari Scott Fitzgerald «la première flapper d'Amérique ", écrit en 1922 l'éloge de cet éphémère modèle de femme, ici traduit de l'anglais :

La Flapper se réveilla de sa léthargie, elle s'arma de précieuses boucles aux oreilles et de grandes doses d'audace, les lèvres très rouges et partit à la bataille. Elle flirtait, car c'était amusant et mettait un maillot de bain moulant parce qu'elle avait la silhouette pour le porter ; elle se maquillait et mettait du fard, car elle n'en avait pas besoin et refusait de s'ennuyer parce qu'elle n'était pas ennuyeuse. Elle savait que les choses qu'elle faisait n'étaient pas celles qu'elle avait toujours voulu faire. 
Les mères n'approuvaient pas que ses fils invitent une flapper?? ? À danser, à prendre le thé, à nager ; mais, surtout qu'elle puisse leur voler le cœur. ${ }^{71}$

Lolina devient ainsi, dès l'âge de douze ans, une "preflapper ", qui préfigure déjà les goûts des femmes modernes des années vingt - avec le retard inhérent à l'Espagne, notamment aux Îles Canaries, cela aura lieu dix ans plus tard - plutôt frivoles et rêveuses. Certes, l'émancipation féminine est encore bien loin à l'époque, malgré ces apparences illusoires et, encore plus loin lorsqu'il s'agit du contexte espagnol, en dépit des efforts de la Seconde République.

Les lettres à Lolina se suivent sur un ton pédagogique qui se veut moderne, du fait qu'Espinosa entame un dialogue d'égal à égal avec l'enfant. En même temps, ces lettres véhiculent, à travers Lolina, les opinions d'Espinosa, qui cherche ainsi à se démarquer des vieilles certitudes esthétiques du $\mathrm{XIX}^{\mathrm{e}}$ siècle. L'article intitulé «Esthétique du bellicisme. Le film moche À l'ouest rien de nouveau " s'amorce ainsi comme l'avis de Lolina elle-même qui, comme tous les enfants et comme Espinosa, déteste cette représentation pathétique de la guerre :

La cruauté, la vieillesse, la tristesse, la honte - lamentation décrépite ou air de vaincu - répugnent, surtout aux enfants. [...]

Elle n'est pas moche la guerre, crois-moi. ${ }^{72}$

1 Les thèses qu'Espinosa bâtit à travers Lolina sont celles qui à l'époque attiraient certains intellectuels vers la puissance des fascismes, en opposition à cette attitude « fâcheusement chétive » des démocraties.

\section{Joséphine}

82 Les lettres à Lolina prennent fin trois jours à peine avant le mariage d'Espinosa avec la sœur de cette dernière, le 14 juin 1932. Pendant sa lune de miel, Espinosa amorce son "Journal d'un poète jeune marié ", comme celui de Juan Ramón Jiménez. La figure de son épouse demeure assez absente de ces chroniques pendant la lune de miel. Elle apparaît au début sous une forme générique, qui se veut probablement humoristique, où la femme devient une épouse comme n'importe quelle autre et l'amour une affaire banale qui dépend du hasard.

Il est curieux de remarquer que dans tous les portraits qu'Espinosa livre de sa femme, elle semble assez passive - sauf quand elle fait des courses -, elle regarde la lune, ou bien elle dort. Josefina semble donc une femme assez silencieuse et, à chaque fois qu'il décrit une situation où il est seul avec sa femme, apparaît l'adjectif « muets ».

Parallèlement à son journal de jeune marié, Espinosa compose des poèmes qui ne seront publiés qu'en 1982. Espinosa avait intitulé le recueil Poèmes a Mme Joséphine. On trouve dans ces poèmes des échos de sensations que l'on voit déjà dans son journal. Le recueil consacre trois strophes, dont les deux premières et la neuvième, au silence et au regard :

2

Éste es el silencio

que yo espero:

galope sin sonar de cascos,

campaña acróbata,

diálogo sin voz;

montaña sin pinar flautista,

fuente muda, 


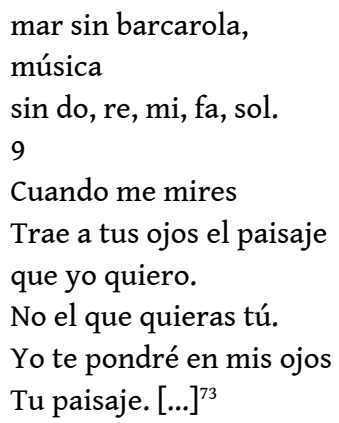

Il faut remarquer dans ces poèmes la simplicité et la fraîcheur qu'Espinosa aime dans le "Romancero" du Moyen-Âge et dans les premières avant-gardes. Le bonheur du je poétique est décrit comme ce "silence qu'il attend", "un dialogue sans voix», une " fontaine muette », ou une " musique » sans notes.

Dans le poème 9 , le je poétique explique en quoi consiste son nouveau regard : il veut découvrir dans les yeux de sa femme le paysage qu'il aura choisi pour elle, afin que leurs yeux deviennent deux reflets de la même image.

Parmi ces vers, le poème 5, qu'Espinosa avait déjà publié en 1929 semble avoir été inspiré par les femmes qui l'attiraient à l'époque, d'après ses lettres; les couturières madrilènes, les femmes sportives du Guadarrama ou, peut-être, María Ana :

5

Mi verso :

aprendiz tuyo,

ganadora de los 200 metros.

De tu cuerpo cálido.

Limpio. Ágil.

Sin retórica.

Medidor de estadios.

Jinete del viento.

Desnudo.

Breve.

Sin sexo. ${ }^{74}$

Il s'agit non seulement d'une simple métaphore de la Nueva literatura d'avant-garde, sans rhétorique inutile, c'est aussi la description d'un corps "d'avant-garde », comme par la suite, celui de María del Pilar Lozada, sportif et agile. Un corps «cavalier du vent $»^{75}$ comme l'était le corps de María Ana, dans l'ode qui lui est consacrée, « cavalière de rêves adverses ".

Espinosa accorde certainement une grande importance à l'apparence esthétique, au point qu'il condamne la Seconde République à cause de ses symboles démodés, dont l'effigie d'une grosse madone, qui ne peut s'adapter aux nouveaux temps :

Face à la grosse madone et son fauve sénile, l'actuel enfant espagnol - le futur républicain d'Espagne - pourra-t-il sentir autre chose qu'une répugnance sensorielle, qu'un profond désenchantement, qu'un appétit d'emblèmes communistes et même d'icônes de l'ancien culte chrétien ?76

90 On a pu voir qu'Espinosa adapte également des mythes traditionnels aux nouvelles tendances d'avant-garde. Ainsi, Dácil devient son contraire: une "tenniswoman» impassible, et Lolita-Alice se métamorphose en enfant qui rêve d'être artiste, mais qui reste au stade d'« avant-flapper ».

91 Mais lorsqu'il s'agit de son épouse, Espinosa a du mal à lui accorder un statut mythique. On a signalé que cela relevait peut-être d'un refus de dévoiler son intimité aux lecteurs, 
car il est désormais un homme marié, ou même à sa femme, par rapport à l'éducation qui prétend que les hommes ne doivent pas montrer leurs sentiments. Quoi qu'il en soit, la figure de l'épouse devient une énigme. Les deux derniers poèmes du recueil Poemas a Mme Joséphine corroborent en partie cette hypothèse, car le je poétique est partagé entre deux types de femmes, la sirène et la pastourelle : la première semble représenter toutes les femmes séductrices et ambiguës, tandis que l'épouse bucolique, est à la fois casanière et salutaire pour l'homme. Cette attitude reproduit un modèle social, celui des Îles Canaries dans les années trente.

Espinosa avait des affinités évidentes avec les futuristes et on a souvent pensé que ce mouvement était conduit par des misogynes invétérés. Mais la réalité est plus complexe. En effet, après leur manifeste de 1909 où on lit « Nous voulons glorifier [...] le mépris de la femme $",{ }^{77}$ les futuristes ont pris des positions progressistes sur le divorce, le droit de vote ou l'égalité dans le travail, sans compter les modèles de femmes très peu conventionnelles qui apparaissent dans leurs œuvres à côté des clichés féminins les plus rétrogrades. Selon Silvia Contarini, les hommes d'avant-garde, concrètement les futuristes, étaient obligés de vivre en contradiction avec eux-mêmes, toujours partagés entre le désir d'amour libre et une réalité sociale éloignée de cet idéal :

[...] Les digressions foisonnent [...] au sujet du grand amour, de la prostitution, du mariage, de la séduction et de l'amour libre. [...] Les futuristes adorent les cocottes, même s'ils font des mariages d'amour; qu'ils encensent les prostituées, même s'ils sont des pères et des maris attentionnés; qu'ils clament leur préférence pour les femmes du peuple, même s'ils fréquentent des femmes de lettres et les dames du monde; qu'ils disent honnir le luxe, même s'ils sont séduits par les femmes élégantes. ${ }^{78}$

Comme les futuristes, Espinosa est partagé entre l'imaginaire et la réalité : il se débat entre la société traditionnelle et bourgeoise canarienne, qu'il voudrait voir évoluer, et les progrès artistiques et politiques du monde moderne. Tous ses articles confirment qu'il est en quête d'un changement radical or, dès qu'il est question de femmes, il ne témoigne pas d'une véritable envie d'affronter les problèmes qu'impliquerait leur émancipation. D'ailleurs, non seulement elles sont reléguées chez Espinosa, quand il s'agit de changements sociaux -la situation de la femme est par ailleurs complètement ignorée dans les manifestes de Gaceta de Arte -, mais elles sont aussi quasiment absentes dans ses écrits journalistiques ou littéraires. De par ses goûts littéraires, Espinosa est influencé par toute la culture misogyne de fin de siècle, qui ne voit pas dans la femme un individu à part entière.

\section{La femme phalangiste}

Le fascisme espagnol, profondément catholique, imposera aux femmes un retour radical en arrière, notamment à celles qui avaient réussi à s'émanciper durant la Seconde République. Il est vrai que les phalangistes, moins orthodoxes que le reste de la droite avant le Décret d'Unification ${ }^{79}$, revendiquent le catholicisme de manière plus culturelle que dogmatique. Mais, en dépit de ce catholicisme de façade, la misogynie est en revanche bien ancrée dans la culture latine. Comme le montre l'article d'Ernesto Giménez Caballero, où il analyse la Seconde République en ces termes: "l'Espagne pourra-t-elle supporter encore longtemps cette protection pseudo-matriarcale? La traditionnelle Espagne de Don Juan pourra-t-elle supporter la victoire du sexe opposé ? » ${ }^{80}$ 
On voit comment, même pour la droite progressiste, les acquis des femmes restent tabous. Mais ce qui relevait du paradoxe et de la provocation durant la Seconde République devient, à partir de 1936, une réalité. Le mouvement phalangiste trouve dans la misogynie et le culte de la masculinité l'un des fondements majeurs de son idéologie. Comme Mussolini, qui comparait la relation du chef à la foule à celle de l'homme face à la femme dominée ${ }^{81}$, les rebelles exaltent les vertus de la virilité durant la guerre pour conduire les hommes au combat.

On compte chez Espinosa des nombreux exemples de cette virilisation profonde des textes. Dans le vocabulaire de la Phalange espagnole les adjectifs pour définir l'essence de la masculinité sont la dureté, la rigidité et la verticalité, par opposition à la féminité, qualifiée de molle. Les femmes sont traitées de faibles créatures influencées par la décadence du cinéma américain et de ses frivoles héroïnes :

De nos jours, le cinéma américain a été l'un des mécanismes de désintégration nationale et d'acculturation les plus puissants. Ressembler spirituellement et physiquement aux frivoles héroönes des frivoles films américains fut l'idéal [...] d'une partie de nos femmes. ${ }^{82}$

Comme dernier exemple, Espinosa consacre une brève réflexion à la femme dans l'essai qu'il écrit à l'occasion de la fête du livre en 1938. Cette digression sur la religiosité de Cervantes, tente de rallier le mythe du Quichotte à la cause de Franco et de la Phalange espagnole. Espinosa attaque les théories que le Professeur Américo Castro avait développées en 1925 dans La pensée de Cervantes. D’après Espinosa, Castro essaie de démontrer que Don Quichotte représente la figure d'un homme de la Renaissance, émancipé de la morale catholique. Espinosa conteste cette perspective, dont la dernière thèse repose sur l'indulgence de Cervantes envers les femmes adultères :

[...] Pour Cervantès - selon le professeur Castro -, la femme mariée contre son gré trompe généralement son mari. Cervantès - continue-t-il - est trop indulgent avec l'adultère [...]. Mais Castro oublie que pour la morale chrétienne, il y a un crime encore pire que l'adultère et c'est la violence de ceux qui ont marié l'adultère contre son gré, et c'est le péché de la femme qui ment devant l'autel de Dieu, quand elle se marie contre sa volonté ; car elle veut tromper Dieu alors que c'est ellemême qu'elle trompe. ${ }^{83}$

On voit que, même l'hétérodoxe Américo Castro, estime que Cervantes est "trop » indulgent à l'égard de l'adultère des femmes qui sont mariées de force. Espinosa rétorque en alléguant que celui qui oblige la femme à se marier à son corps défendant est le coupable. Mais, chez Espinosa, le summum du péché est atteint, curieusement, par la femme, qui trompe Dieu devant l'autel.

Sous le franquisme, la phalange espagnole s'appropriera des mythes comme Thérèse de Jésus, patronne des sections féminines de la phalange espagnole, afin d'endoctriner les femmes dès leur plus jeune âge. Il faut vivre en accord avec la Religion catholique, qui leur offre deux voies: le mariage et la maternité ou la vie monacale. Les mythes de déesses seront désormais condamnés aux « enfers » catholiques, jusqu'à l'avènement de la démocratie en Espagne. 


\section{Conclusion} simple convention dans la représentation des femmes, toujours hésitantes entre la banalité et le mal, ne l'est finalement pas tout à fait. Elles sont les objets du regard et du désir d'un sujet masculin qui cherche à exorciser la violence de ses angoisses. Privées de parole, c'est justement ce silence qui fait leur redoutable mystère : il exprime à la perfection l'inquiétante fatalité incarnée par ces femmes définitivement épineuses. 


\section{NOTES}

1. Lors du discours de l'acte de fondation de «Phalange espagnole », qui eut lieu au Théâtre de la Comédie de Madrid le 29 octobre 1929. "En un movimiento poético nosotros levantaremos este fervoroso afán de España" (Dans un mouvement poétique, nous hisserons ce fervent désir d'Espagne).

2. Pourtant, les auteurs étant eux-mêmes des petits-bourgeois, il s'agit plutôt de critiquer une condition morale de conformisme social, qu'une condition économique.

3. Il suffit de lire le $2^{\mathrm{e}}$ manifeste international surréaliste, pour ressentir l'esprit subversif dont G.A. s'est épris : «Contre la patrie, qui divise les hommes, les faisant s'affronter en ennemis [...]. Contre la religion, tyrannie spirituelle et économique, qui se met au service des exploiteurs pour différer la venue d'une nouvelle heure collective. » № 2 Bulletin international du surréalisme, Santa Cruz de Tenerife, octobre 1935. Publié par le groupe surréaliste París (sic) et « G.a. » Tenerife (îles Canaries). Sur deux colonnes, l'une en espagnol et l'autre en français.

4. Agustín Espinosa, Crimen, première édition, ediciones de Gaceta de Arte, Las Palmas de Gran Canaria, 1934 ; traduit en français par Gérard de Cortanze, Paris, la Différence, 1989.

5. César Muñoz Arconada, "Un joven puede ser comunista, fascista, cualquier cosa, menos tener viejas ideas liberales", dans " Politique et littérature : une enquête à la jeunesse espagnole » (La citation est la réponse à la troisième question), La Gaceta Literaria, $\mathrm{n}^{\circ} 25,1^{\mathrm{er}}$ janvier 1928. Cité par J. M. Bonet dans le prologue à Ernesto Giménez Caballero. Entre la vanguardia y el fascismo d'Enrique Selva, éd. Pretextos, Valencia, 2000, p. 10-11.

6. Paradigmes signalés par Pierre Brunel dans l'introduction du Dictionnaire des mythes féminins, dirigé par Pierre Brunel (ed), Monaco, éd. du Rocher, 2002.

7. Hans Bellmer, La poupée, 1933-1936. Cette œuvre inspirera par la suite les représentations artistiques d'une femme monstrueuse qui exprime la peur et le désir. Agustín Espinosa déclinera les métamorphoses de cette figure dans son roman surréaliste Crimen. Par ailleurs, l'influence de cette figure a été décisive. En Espagne, le film Grandeur nature réalisé par Luis García Berlanga en 1973, raconte l'amour fou d'un homme -interprété par Michel Piccoli- pour un mannequin articulé.

8. Élisabeth Badinter, $X Y$, «La crise de la masculinité aux $\mathrm{XVII}^{\mathrm{e}}$ et $\mathrm{XVIII}^{\mathrm{e}}$ siècles en France et en Angleterre » et "La crise de la masculinité au tournant des $\mathrm{XIX}^{\mathrm{e}}$ et $\mathrm{XX}^{\mathrm{e}}$ siècles ", in De l'identité masculine, Paris, Odile Jacob, 1992, p. 24-40.

9. Claude Cahun, « Prenez garde aux objets quotidiens », Cahiers d'Art, 1936.

10. Les autoportraits photos de Claude Cahun rappellent le portrait de la journaliste Sylvia von Harner, de 1926, par Otto Dix. On peut se demander si l'intention d'Otto Dix, en tant qu'homme des avant-gardes, n'était pas ironique dans ce tableau, étant donnée l'arrogance intellectuelle que la protagoniste semble montrer, ses bas, qui apparaissent défaits et sa robe à carreaux, opposée à la décoration Art nouveau. Or l'œuvre d'Otto Dix est marquée par une ironie bien plus violente que celle que l'on observe dans ce tableau qui accorde, malgré tout, une existence à ces femmes modernes qui revendiquent l'indéfinition sexuelle à l'époque.

11. André Breton et Louis Aragon, «Le cinquantenaire de l'hystérie (1878-1928) », La Révolution surréaliste, $\mathrm{n}^{\mathrm{o}}$ 11, 1928.

12. À travers l'hypnose de ses patients, Charcot reproduit les symptômes de l'attaque hystérique pour suggérer que l'hystérie n'est pas une maladie organique. Sigmund Freud est son élève d'octobre 1885 à février 1886. Il suit ses cours avec passion et s'inspire de ses travaux pour développer l'idée centrale de la psychanalyse, c'est-à-dire, que la majeure partie des maladies mentales ne sont pas d'origine physique ou organique, mais relèvent d'une instance psychique, qu'il appellera l'inconscient. 
13. Paul Richer, Études cliniques sur l'hystéro-épilepsie ou grande hystérie; précédé d'une lettre préface de M. le professeur J.-M. Charcot, Paris, A. Delahaye et E. Lecrosnier, 1881.

14. Phase "épileptoïde avec tétanisation brusque des muscles de tout le corps ", convulsions cloniques, enfin résolution. Phase «des attitudes illogiques ou contorsions et de grands mouvements " allant jusqu'à l'opisthotonos, à laquelle Charcot donna le nom de "clownisme ». Phase "des attitudes passionnelles ou des poses plastiques» (catalepsie) pendant laquelle la malade est sujette à « des hallucinations qui la ravissent ».

15. «Contracture de tous les muscles postérieurs du corps, donnant à celui-ci une attitude caractéristique: arqué en arrière, le malade, quand on l'allonge sur le dos, ne repose sur sa couche que par les talons et l'occiput ", Dictionnaire en ligne, Larousse 2015.

16. L'influence dans les Arts de cet imaginaire hystérique sera significative par la suite, comme le montre la sculpture de Louise Bourgeois, Arc d'Hystérie, créée en 1993.

17. Salvador Dalí viendra confirmer cette jouissance féminine dans le photomontage «Le phénomène de l'extase », en 1935.

18. «La liberté de ton des érotiques surréalistes n'a rien à envier aux livres qu'il y a peu on plaçait dans les bibliothèques sous la cote «Enfer » ni même de ceux qu'on vendait «sous le manteau », Jacqueline Chénieux-Gendron, «Il y aura une fois ». Une anthologie du surréalisme, Paris, Gallimard, 2002, p. 24-25.

19. Nous reprenons ici le titre fameux du film de Luis Buñuel, Cet obscur objet du désir, 1977. Celuici s'inspira d'ailleurs du roman de Pierre Louÿs, publié en 1898, La Femme et le pantin, dont on trouve aussi des échos chez Espinosa, notamment dans Crimen. L'expression originale dans le roman est "ce pâle objet du désir », et cet adjectif est encore mieux adapté aux inclinations notamment du point de vue épidermique- d'Espinosa.

20. Bibliothèque Augustinienne. Les cuvres de saint Augustin, Troisième série: La grâce, BA 23 : Premières polémiques contre Julien (par François Joseph Thonnard, Emile Bleuzen et Albert De Veer, 1974) p. 41-289 : «Mariage et concupiscence ». Saint Augustin est sous l'influence de Platon - notamment à travers Cicéron, du néoplatonisme de Plotin et de Porphyre, les doctrines des manichéens et, évidemment, de la Bible et de la tradition chrétienne transmise principalement par Saint Cyprien de Carthage et Saint Ambroise de Milan. Voir Le Magazine Littéraire. Saint Augustin, la passion du Philosophe, "Sexualité et gouvernement de soi », Michel Senellart, no 439, février 2005, p. 59-61.

21. Dès le premier mot, celui du titre, Espinosa utilise le terme «Lesbia » dans le sens propre au $\mathrm{XIX}^{\mathrm{e}}$ siècle, c'est à dire, celui dont Baudelaire voulait se servir en 1845 pour intituler son recueil Les Fleurs du Mal. Cet usage fait notamment référence à Sapho ou, peut-être aussi, à Lesbia, la maîtresse poétique de Catulle. John E. Jackson, «La question de Lesbos », dans Baudelaire: du dandysme à la caricature, l'année Baudelaire, p. 101-108, Paris, Champion, 2003.

22. Agustín Espinosa, «Lesbia ", sans date, probablement rédigé en 1917. Dans “Textos inéditos y no recogidos en volumen", annexe de l'édition de la Thèse d'État de Miguel Pérez Corrales, Agustín Espinosa, entre el mito y el sueño, ediciones del Cabildo Insular de Gran Canaria, Las Palmas de Gran Canaria, 2 tomes, 1986, p. 652-653.

23. Frédéric Monneyron, Dictionnaire des mythes d'aujourd'hui, Pierre Brunel, (ed.), entrée « femme fatale », op. cit., p. 749. Elle a néanmoins, littérairement, des personnalités diverses : La figure qui s'impose en cette fin de $x^{2}{ }^{e}$ siècle n'identifie pas en fait un type unique de femme. Si la lesbienne, très présente dans les romans des décadents, occupe une place à part, deux types de femme représentent plus précisément en revanche la féminité dangereuse. C'est tout d'abord l'«allumeuse ", celle qui séduit les hommes mais se refuse à satisfaire leurs désirs [...]. C'est ensuite, à l'inverse, celle qui se donne à tous, la courtisane, voire la nymphomane - ou du moins la femme aux mœurs dissolues [...]. (Ibid., p. 750).

24. Par ailleurs, « il faut noter également que la nature mortifère qu'on attribue à ces femmes est due, non seulement à la société misogyne de l'époque, mais aussi à leur identification à la 
syphilis » Frédéric Monneyron, Dictionnaire des mythes d'aujourd'hui, Pierre Brunel, (dir.), entrée «femme fatale », ibid., p. 751.

25. Mireille Dottin-Orsini, Magazine Littéraire: Les énervés de la Belle Époque, « Misogynies fin-desiècle ", no 288, mai 1991, p. 20-23.

26. Agustín Espinosa, "Exótica”, juin, 1920. Textos inéditos y no recogidos en volumen, p. 654.

27. Cette époque a été qualifiée par les spécialistes d'Espinosa de moderniste pré-surréaliste, Comme M. Pérez Corrales a décidé avec justesse de la qualifier, étant donnés les signes anticipateurs de Crimen. Voir Agustín Espinosa, entre el mito y el sueño, opus cit., p. 552.

28. Agustín Espinosa, "Exótica”, op. cit., p. 654.

29. «D'ailleurs, si les décadents ont évoqué la sacralisation de l'amour vénal, c'est grâce aux découvertes archéologiques du XIX ${ }^{\mathrm{e}}$ siècle. » Il faut attendre les recherches archéologiques du XIX siècle pour voir revenir la figure de la prostituée sacrée, éclipsée par les religions monothéistes. Mais la tendance syncrétique de l'époque assimile les courtisanes historiques de plusieurs civilisations en leur prêtant les traits de la femme fatale. » (C. Boula et V. Fortin, dans Dictionnaire des mythes féminins, Pierre Brunel (ed.), entrée « prostituée sacrée », p. 1590-1598, citation de « la prostituée sacrée dans l'imaginaire "décadent" », op. cit., p. 1596.)

30. Agustín Espinosa, "Bajo el signo de Demos: elogio de Luisa Santana, tanguista de las palmas", publié dans La Prensa, le 4 novembre de 1931, article repris dans Textos, p. 119-120.

31. Agustín Espinosa, Crimen, op. cit., "Hiver. Parade”, p. 88. « Si dans mon fichier intime apparaît le crime du buste sous le signe d'Olalla Pineda, vous savez déjà pourquoi j'ai amené ce nom saint et pourquoi j'ai évité, aussi, le vrai. "

32. Dans Crimen, les seins de la statue d'un jardin publique disparaissent pendant la nuit.

33. Ces deux figures seront aussi source d'inspiration pour Lorca, créateur majeur de mythes féminins espagnols : Federico García Lorca, Romancero Gitano, "Martirio de Santa Olalla" de 1928 et la pièce de théâtre Mariana Pineda, de 1925, dont la première a lieu à Barcelone en 1927.

34. Agustín Espinosa, "Bajo el signo de Demos: elogio de Luisa Santana, tanguista de las palmas", Textos, op. cit., p. 120.

35. Agustín Espinosa, ibid., p. 119.

36. Hans Bellmer, Die Puppe, 1934 maquette pour « Les jeux de la poupée », 1938.

37. Agustín Espinosa, "El traje de novio", dans La Nueva literatura, La Tarde, 21 juin, 1929, Textos, p. 43-44.

38. Ibid., p. 43.

39. Rafael Alberti, Cal y Canto, “A Miss X, enterrada en el Viento del Oeste”, écrit entre 1926 et 1927. Publié par Revista de Occidente à Madrid, en 1929, la même année que l'article d'Espinosa. Il faut également noter que Felipe Ximénez de Sandoval, militant phalangiste, publie Tres mujeres más Equis (novela lírica), à Madrid, éd. Ulises, col. Valores Actuales, CIAP, 1930.

40. Agustín Espinosa, "Oda a María Ana, primer premio de axilas sin depilar", publié dans Extremos a los que ha llegado la poesía española, oㅡ 1, mars 1931.

41. Ibid.

42. Si l'on tient compte de la manière dont Espinosa a écrit Crimen, on peut très bien imaginer que l'introduction a été ajoutée, a posteriori, à un poème qu'il avait composé sous l'effet de l'extase amoureuse.

43. Miguel Pérez Corrales, publie dans “Archipélago Literario: Agustín Espinosa, 1997”, El Día, Santa Cruz de Tenerife, 19 avril 1997, cette lettre d'Agustín MIRANDA à ESPINOSA du 22 mars 1931.

44. Agustín Espinosa vivait à l'époque avec son ami Agustín Miranda.

45. Les aisselles de María Ana ne relèvent pas seulement du jeu, elles ont une dimension érotique claire : à travers la célébration des poils, qui s'éloignent des convenances esthétiques de l'époque, Espinosa dépasse le surréalisme, en instaurant la vraie désacralisation de la femme, devenue «femelle » poilue. Ce poème a toujours été lu comme un texte ludique ou délirant. Or, Espinosa 
se situe, grâce à lui, dans une position marginale par rapport aux avant-gardes, au-delà de l'émerveillement ou du ludisme, et il élève un sujet vulgaire, destiné aux enfers des bibliothèques, à la catégorie de poésie libertaire.

46. Agustín Espinosa, Crimen, op. cit.

47. Agustín Espinosa, Crime, traduit de l'espagnol par Gérard de Cortanze, la Différence, 1989, p. 9-10

48. Ibid., p. 11-12.

49. Agustín Espinosa, Crimen, op. cit., p. 13.

50. Agustín Espinosa, "El traje de novio", in La Nueva literatura, La Tarde, 21 juin, 1929, Textos, p. 43.

51. Agustín Espinosa, Crimen, "Primavera. Luna de miel”, op. cit., p. 59.

52. Ibid, p. 59-60.

53. Agustín Espinosa, Crimen, "Primavera. Hazaña de sombrero", op. cit, p. 62.

54. En hommage à l'article de Mariano José de Larra «La Nuit de Noël de 1836 ». Ce fragment s'inspire d'un texte que Mariano José de Larra, l'écrivain romantique, écrivit un mois et demi avant son suicide. L'écrivain y reconnaît l'excès de son désir et son impuissance par l'intermédiaire de son domestique qui, ayant trop bu, lui avoue violemment ce qu'il pense de lui. 55. Agustín Espinosa, Crimen, "Primavera. La nochebuena de Fígaro", op. cit., p. 63.

56. Agustín Espinosa, Crimen, "Epílogo en la isla de las maldiciones", op. cit., p. 83-84.

57. Ivana Rota, cite le cas de Lilí Álvarez (1905-1998), victorieuse du Campeonato de Cataluña de Automovilismo en 1924, du Roland Garros catégorie doubles en 1929, et championne espagnole de ski en 1941. Voir Ludus. Cine, arte y deporte en la literatura española de vanguardia, éd. de Gabrielle Morelli, Madrid, Pre-textos, 2000, p. 72. Lilí Álvarez est également l'auteure de plusieurs livres qui attestent un mélange de féminisme et de religiosité.

58. Dans l'édition de Miguel Pérez Corrales et Alfonso Armas Ayala, Textes Agustín Espinosa: Textos (1927-1936), éd. Aula de Cultura de Santa Cruz de Tenerife, Santa Cruz de Tenerife, 1980.

59. Luisa Santana, artiste malgré son anonymat, ne sera pas évoquée ici, car elle a déjà été associée au mythe de la femme fatale.

60. Agustín Espinosa, "Bilans de mer et de terre: le contre-mythe de Dácil », La Prensa, $1^{\text {er }}$ septembre, 1931, Textos, p. 104-105.

61. Fille du roi Bencomo - Mencey de Naoro -, et sœur de Ruimán et Rosalba.

62. Agustín Espinosa, "Balances de mar y tierra: el contramito de Dácil”, La Prensa, $1^{\text {er }}$ septembre, 1931, Textos, p. 104-105.

63. Ibid., p. 104. "La symphonie en blanc fut un sujet cher à d'autres soifs et à des rêves d'autres âges. Elle fut trop louangée au XIX ${ }^{\mathrm{e}}$ siècle, pour ne pas fatiguer à l'aube du Xxe . »

64. Agustín Espinosa, “La Infantina de Nivaria”, La Prensa, $1^{\text {er }}$ mai, 1932, Textos, p. 166-173.

65. Ibid., p. 173.

66. Malgré de nombreuses références au pouvoir masculin et à la fidélité féminine, les mythes Guanches ne seront plus jamais évoqués par Espinosa durant sa collaboration avec les journaux phalangistes. Les causes en sont évidentes : le retour à l'idéal d'une Espagne impériale exigeait, en effet, une forte centralisation des icônes et des mythes nationaux. Ainsi, toute particularité régionale est réduite au silence et cela jusqu'à la mort de Franco en 1975.

67. Lolina Boissier Castellano, morte le 20 décembre 2002 à Tenerife.

68. Louis Carroll, pseudonyme de Ch. L. Dodgson, Alice's Adventures in Wonderland (1865), Through the Looking-Glass, and What Alice Found There (1872), Alice's Adventures Under Ground (1886).

69. D'après les informations de son beau-fils Sebastián Arozena marié à Begoña de Varcárcel Boissier, Lolina est née en 1920, donc huit ans après sa sœur, née en 1912.

70. Agustín Espinosa, “Carta provincial a Lolina. viajeros de Nueva York: un vasco en la ciudad de los rascacielos", La Provincia, Las Palmas, 27 février 1932. Textos, p. 134-136, ici p. 134-135. L'écrivain et journaliste new-yorkais Waldo Frank était très célèbre en Espagne en 1932. 
71. Zelda Sayre Fitzgerald, "Eulogy on the Flapper", Metropolitan Magazine, nº 55, juin, 1922.

72. Agustín Espinosa, “Carta semanal a Lolina. Estética de lo bélico: la fea película Sin novedad en el frente", La Provincia, 13 mars, 1932. Textos, p. 137-139, ici, p. 137, 138, 139.

73. Agustín Espinosa, Poemas a Mme Joséphine, La laguna, 1982. Publié sous la direction de Sebastián de la Nuez. Écriture établie en 1932, p. 7-8 et p. 12.

74. Agustín Espinosa, Ibid. Ecriture établie en 1932, même si certains poèmes ont été écrits en 1929. Ce poème, concrètement, a été publié en 1929 sous le titre "Poemas", dans la "la Nueva Literatura", page culturelle du journal La Tarde, le 23 août, 1929, Textos, p. 45.

75. Il ne faut pas oublier non plus le personnage de Rafael Alberti, Cal y Canto, "A Miss X, enterrada en el Viento del Oeste". Dans ce poème le corps de l'aimée chevauche le vent au lieu d'être enterrée par lui.

76. Agustín Espinosa, “Ars reipublicae. Iconos del ochocientos y músicas de taran-tan-tan”, Gaceta de arte, $\mathrm{n}^{\circ} 19$, septembre, 1933. Textos, p. 234-236, ici, p. 234-235.

77. Filippo Tommaso Marinetti, «Fondation et manifeste du futurisme », Le Figaro, 20 février, 1909.

78. Silvia Contarini, La Femme futuriste. Mythes, modèles et représentations de la femme dans la théorie et la littérature futuristes (1909-1919), Paris, Presses Universitaires de Paris 10, 2006, p. 172-172.

79. Décret du 19 avril 1937, qui assignait le pouvoir au Général Franco après la mort de tous les généraux à l'origine du soulèvement du 18 juillet 1936, neuf mois plus tôt.

80. Ernesto Giménez Caballero, El Robinsón literario de España (o la República de las letras), $\mathrm{n}^{\circ} 115,1^{\mathrm{er}}$ octobre 1931.

81. Julio Rodríguez Puértolas, Literatura fascista española Historia, éd. Akal, Madrid, 1986, t. I, p. 28-30.

82. Agustín Espinosa, "Cuento de Navidad", inédit, décembre 1936.

83. Agustín Espinosa, "Fiesta del Libro", inédit, décembre 1938. Souligné dans l'original.

84. D'après l'ouvre d'Edmund Burke, dans A Philosophical Enquiry into the Ideas of the Beautiful and Sublime, 1757, dont s'inspire par la suite Emmanuel Kant.

\section{RÉSUMÉS}

L'étude de l'œuvre d'Espinosa devient un outil inestimable pour le déchiffrage de certains paradigmes féminins de son époque. Quatre archétypes de femme, prédominants dans la littérature fin de siècle et celle des premières décennies $\mathrm{du} \mathrm{xx}^{\mathrm{e}}$ siècle, séduiront l'auteur : La « femme fatale " du «modernismo » espagnol; la "poupée surréaliste», dénomination choisie d'après une longue lignée de poupées artistiques : Kokoshka en 1918, Lotte Pritzel en 1919, Hans Bellmer en 1933 ; la «Femme futuriste », inspirée des archétypes féminins des années vingt, générés par des films comme Metropolis de Fritz Lang et, finalement, la femme phalangiste, semblable à celles du Futurisme italien et modèle de référence pour les membres de la section féminine - branche de la phalange espagnole créée en 1934.

El estudio de la obra de Espinosa puede convertirse en un instrumento inestimable para descifrar ciertos paradigmas femeninos de su época. Cuatro arquetipos de femme, predominantes en la literatura de finales del siglo XIX y de las primeras décadas del Xx, seducirán al autor: la "mujer fatal" del Modernismo español; la "muñeca surrealista", denominación inspirada de un gran linaje de muñecas artísticas: las de Kokoshka en 1918, Lotte Pritzel en 1919 y Hans Bellmer en 
1933 ; la "mujer futurista", inspirada en los arquetipos femeninos de los años veinte, generados por películas como Metrópolis de Fritz Lang y, finalmente, la mujer Falangista, parecida a las del Futurismo italiano y modelo de referencia para los miembros de la Sección Femenina -rama de la Falange Española creada en 1934.

INDEX

Palabras claves : muñeca, mujer fatal, modernismo, decadentismo, simbolismo, surrealismo, futurismo, sección femenina de la falange española

Mots-clés : poupée, femme fatale, modernisme décadentisme, symbolisme, surréalisme, futurisme, section féminine de la phalange espagnole

\section{AUTEUR}

\section{BEATRIZ GÓMEZ GUTIÉRREZ}

Paris IV - Paris Sorbonne 